\title{
To evaluate the comparative efficacy of various drug combination via epidural route in treatment of pain in patients of intervertebral disc herniation.
}

\author{
Dr Gaurav Chopra, Dr Nidhi Srivastav
}

\section{Introduction}

Low back pain is a major public health problem and is beginning to exhibit epidemic proportion. Back pain is a main reason for which people under $45 \mathrm{yrs}$ limit their physical activities ${ }^{1-4}$. Major risk factors include heavy lifting, twisting, bodily jerks, obesity and poor postures ${ }^{5}$.

Low back pain may originate from many spinal structures including ligaments facet joints, the vertebral periosteum, the Para vertebral musculature, annulus fibrosis and spinal nerve roots.

Most common process is age related degenerative processes in the vertebral discs and facet joints. In patients of PIVD, there is an inflammatory response associated with acute disc herniation and this inflammation can lead to direct neuronal activity as well as swelling and mechanical compression of the nerve within the inter vertebral foramina ${ }^{6}$.

This study was done to compare different combinations of local anaesthestic, an opoid and a steroid in epidural space for their analgesic potential. Each group of drug has its own specific property which caused pain relief and help mobilize patients as soon as possible.

\section{Method and Material}

After taking approval from ethical committee and informed consent from the patient the present study was conducted on patients of either sex, of any age and having symptoms of low backache with radiculopathy, coming to the pain clinic. Exclusion criteria: A)any systemic disease that compromised organ function ,B) patients with coagulation defects, which may results in epidural haematoma formation and spinal cord compression. C) Local sepsis at the site of proposed epidural injection, D) proven allergy to the intended drug, E) unstable spinal fracture, F) patient's refusal to undergo the procedure and spinal deformity

The patients were randomally allocated to three groups of 20 patients each according to computer generated numbers. The drugs were prepared by the anesthetist who was not involved in the data interpretation. Drug combinations used were-

Group A: Methyl prednisolone $2 \mathrm{mg} / \mathrm{kg}+0.25 \%$ Bupivacaine hydrochloride 3-5 $\mathrm{ml}$ bolus.

Group B: Methyl prednisolone 2mg/kg+Tramadol hydrochloride $2 \mathrm{mg} / \mathrm{kg}+0.25 \%$ Bupivacaine hydrochloride 3-5 $\mathrm{ml}$ bolus

Group C: Tramadol hydrochloride $2 \mathrm{mg} / \mathrm{kg}+0.25 \%$ Bupivacaine hydrochloride $3-5 \mathrm{ml}$ bolus.

Pre anaesthetic assessment was done with special reference to neurological status of the patient and pain was assessed according to the visual analog scale. Local anaesthetic sensitivity was done. Patient was kept nil per oral for $4 \mathrm{hrs}$ before the procedure. I.V line was established and appropriate iv fluid was started. After reassuring the patient the procedure was performed in sitting or lateral position as per his/her comfort. Under all aseptic precautions as per institute protocols Tuohy's needle was introduced into the prolapsed interspace .Epidural space was ensured by hanging drop method and loss of resistance technique.

Test dose of drug was injected thereafter drug combination was injected into epidural space through a Tuohy's needle, into the affected space.

Hemodynamic parameters like systolic, diastolic, mean arterial pressure, heart rate and respiratory rate were recorded every 6 min for 30 minutes and then 15 minutes for next 90 minutes.

3 injections were given to the patient: One - At the time of first admission the neurological assessment \& pain scale was assessed uptil $24 \mathrm{hrs}$. Patient was called for follow up his neurological status \& pain scale was again assessed and noted. Then the second injection was given after 3 weeks. The patient was again asked to follow up after 3 months. On admission again the neurological status and pain scale were assessed and the $3^{\text {rd }}$ dose of the drug combination given. The patient was asked for follow up for assessment of long term pain relief.

Statistical analysis:

\section{Results:}


There was no significant difference in the demographic data, level of the offending disc and duration of pain. (Table 1) There was a female preponderance in the study $58.33 \%$. Majority of the patients in the study $53.3 \%$ resided in the hilly region. Radiating leg pain and pain hampering daily routine activities was the predominant criteria to take up the patient for epidural analgesia.

Improvement of SLR was calculated by computing the difference of improvement in the degree of SLR before and after various fixed intervals in the affected leg. There was improvement in SLR in all the 3 groups just after the injection due to the effect of local anaesthetic, while in the Group C there was no improvement in SLR at 3 weeks and 3 months period due to the absence of steroid in this group (Methyl Prednisolone). (Table 2)

\section{Discussion:}

The lifetime incidence of low back pain has been reported to be $60-90 \%$ with an annual incidence of $5 \%{ }^{7}$. Low backache is a very old ailment of human beings, which appears to be due to anatomical, architectural and physical activity, of the homo sapiens once they assume erect posture ${ }^{6-8}$. The problem of backache is compounded by aging but it is not very rare in the adolescent and adults of $3^{\text {rd }}-4^{\text {th }}$ decade.

In accordance with the previous studies majority of the patients were in the age group 31-40years. ${ }^{9-11}$ This emphasizes the fact that lumbar disc herniation warranting prompt management is predominantly a problem of the middle age group more commonly affecting the productive age group of the society causing loss of working hours.

In contrast to study by Loy TTT et $\mathrm{al}^{12}$ we observed a female preponderance owing to the fact that most patients belonged to the hilly regions, in which the females are the ones who do most of the manual work like lifting heavy logs of woods on head, further more females of the peri-menopausal groups are prone to osteoporotic changes and in the post partum period the ligaments are lax due to effect of progesterone.

All the patients were given three injections and before giving the injections during the follow up period the VAS and SLR improvement was noted to evaluate whether the previous injections were effective in relieving the pain. The rationale for repeating the doses of the injections irrespective of the improvement was that steroid directly or indirectly inhibit the synthesis or release of a number of inflammatory substances including phospholipase A2, arachdonic acid its metabolite TNF- $\alpha$, IL1 and prostaglandin E2 which are released by the inflamed disc and for the inflammation to fully subside it can take some time. ${ }^{13,14}$

Aurelianus clearly described that symptoms of low backache radiating towards the lower limbs arose from the lumbosacral spine following traumatic lesions. ${ }^{15}$ Several modalities of treatment are available for backache, epidural analgesia being one of them.

Opioids produce their analgesic effects by enhancing the actions of endogenous opioids peptides at specific opiate receptors in the CNS. Tramadol is a centrally acting analgesic that has less respiratory depressant effects by virtue of its 6000 fold decreased affinity for $\mu$ receptors as compared to morphine. It also inhibits serotonin and nor epinephrine receptors in the spinal cord and has no reported neural toxicity. Accordingly Tramadol has potential to provide effective postoperative analgesia with no risk of respiratory depression after central neuraxial blockade. ${ }^{16}$

Bupivacaine is a fast acting local anesthetic used for temporary pain relief. Although used primarily for pain relief, local anesthetics act as flushing agents to detect the chemical or immunologic agents that promote inflammation.

Saline is used to dilute the local anaesthetic or act as a flushing agent to dilute the chemical or immunologic agents that promote inflammation. The rationale behind injecting steroid into the same epidural space adjacent to the spinal nerve is that it combats inflammatory response associated with acute disc herniation and reduces the pain. ${ }^{17}$

Steroids have a number of anti inflammatory properties and an inhibiting effect on fibre conduction. Steroids decrease neuropeptides such as calcitonin generated peptide and substance $\mathrm{P}$ that are involved in neurogenic inflammation it also induces the production of postsynaptic NMDA antagonist. ${ }^{17}$

We observed that group A and B in which epidural steroid injection was used along with the local anaesthetic Bupivacaine and opioid tramadol were effective in relieving chronic low back pain as evidenced by the data subjected to statistical analysis and it was found that there was significant improvement in group A and B in VAS and SLR test as compared to group C.

In our study it was observed that in-group A and B in immediate post epidural period and later on at 24 hrs, 3 weeks and 3 months; there was a constant improvement in the SLR and VAS scores due to the fact that transient temporary pain relief was provided by the local anaesthetic and opioid while the long-term pain relief was provided by the steroid by reducing the inflammation. On the contrary, In group C in which steroid was not used, there was only temporary pain relief after the injection, but the pain scores and SLR reduced to pre injection valves after some time. Therefore, justifying the fact that when steroids are injected directly into the affected space, they reduce the pain inflammation present in the nerves which are compressed due to the prolapsed disk and provide pain relief. 
Back pain with or without radicular symptoms may be a consequence of a biochemical or mechanical process, with the development of the latter entirely dependent on the former.

As seen in the present study there is significant evidence that indicates that it is inflammation which underlies the radicular pain associated with symptoms of lumbar disc herniations lumbar radiculopathy secondary to a disc protusion is nearly the result of mechanical compression of a spinal nerve or nerve root. This inflammatory process is believed to sensitize the dorsal root ganglia to all incoming stimuli.

We recommend employing epidural steroid installation in the management of lumbar radicular syndromes and our study demonstrates the statistically significant benefit of this therapeutic approach.

\section{Conclusion}

To conclude, our study proves that drugs used in group 1 were efficacious in relieving pain in PIVD patients.

The second group drugs were equally efficacious in relieving pain but the quality of analgesia and improvement in SLR was better.

The drugs used in-group 3 provided only temporary pain relief, there was no long-term pain relief with drugs of the $3^{\text {rd }}$ group.

Hence proving the fact that steroids are most efficacious in providing pain relief in PIVD patients.

\section{References:}

[1] Deyo RA. Low back pain. Sci Am 1998; 279: 48-53.

[2] Bratton RL. Assessment and management of acute low back pain. Am FAM Physician 1999; 60: 2299-308.

[3] Lively MW. Sports medicine approach to low back pain south Med J 2002; 95: 642-6.

[4] Hart LG, Deyo RA, Cherkin DC: Physician office visits for low pain: frequency, clinical circulator and treatment patterns from a US national survey Spine 1995; 20: 11-9.

[5] Anderson GBJ. The epidemiology of spinal disorders. The adult spine; 1997; 2:93-141.

[6] Lee HM. Weinsteen JN, Meller ST. Rupture of the inter vertebral disc. Spine 1998; 23: 1191-6.

[7] Anderson GB. Epidemiologic aspects on low back pain in industry. Spine 1981; 6: 153-60.

[8] Cotter MM, Loomis DA, Simpson SW, Latimer B, Hernandez CJ (2011) Human Evolution and Osteoporosis-Related Spinal Fractures. PLoS ONE 6(10): e26658. doi:10.1371/journal.pone.0026658

[9] Green LN. Dexamethasone in the management of symptoms due to herniated lumbar disc. J Neural Neurosurg Psychiatry 1975; 38; 1211-7.

[10] Saal JS, Sibley R, Dobrow R, Reynolds J, Saal JA, White AH. Lumbar spine 1991; 12: 143-6.

[11] Naylor A. the biochemical changes in the human intervertebral disc in degeneration and nucleur prolapse. Orthop Clin North Am 1971; 2: 343-58.

[12] Tony TT Loy. Epidural steroid injection for sciatica. An analysis of 526 consecutive cases with measurement and whistle test. Journal of orthopaedic surgery. 2000; 8: 39-44.

[13] Waddell G, Somerville D, Henderson I, Newton M. objective clinical evaluation of physical impairment in chronic low back pain. Spine 1992; 17: 617-28.

[14] Van Tulder MW, Koes BW, Booker LM: Conservative treatment of acute and chronic non-specific low back pain: Spine 1997; 22: 2128-56.

[15] Weinstein SM, Herning SA, Derby R. Contemporary concepts in spine care. Spine 1995; 20: 1842-6.

[16] Vickers, U - Flahery D. Tramadol. Anaesthesia. 1992; 47: 291-6.

[17] Ito R. the treatment of low back pain and Sciatica with epidural corticosteroids injection. Nippon Seikeigella Gakki Zasshi. 1971; 45: 769-77.

\begin{tabular}{|c|c|c|c|c|}
\hline \multirow{6}{*}{$\begin{array}{c}\text { Table 1: } \\
\text { Demogra } \\
\text { phic } \\
\text { profile of } \\
\text { the } \\
\text { various } \\
\text { groups }\end{array}$} & & Group A & Group B & Group C \\
\hline & $\begin{array}{l}\text { Age } \\
(\text { Mean } \pm \text { SD })\end{array}$ & $35.5 \pm 5.5$ & $37.5 \pm 8.6$ & $37.6 \pm 5.2$ \\
\hline & SEX(M:F) & $10: 10$ & $8: 12$ & $7: 13$ \\
\hline & Hilly: Non Hilly & $9: 11$ & $13: 7$ & $10: 10$ \\
\hline & $\begin{array}{l}\text { Level of offending disc } \\
\text { L3-4/L4-5/L5-S1 }\end{array}$ & $4 / 13 / 3$ & $3 / 13 / 4$ & $5 / 11 / 4$ \\
\hline & $\begin{array}{l}\text { Duration of pain(months) } \\
0-6 \mathrm{~m} / 6-12 \mathrm{~m} />12 \mathrm{~m}\end{array}$ & $12 / 1 / 7$ & $9 / 3 / 8$ & $13 / 1 / 6$ \\
\hline
\end{tabular}


Fig 1: Comparison of VAS Score of different groups at different time interval

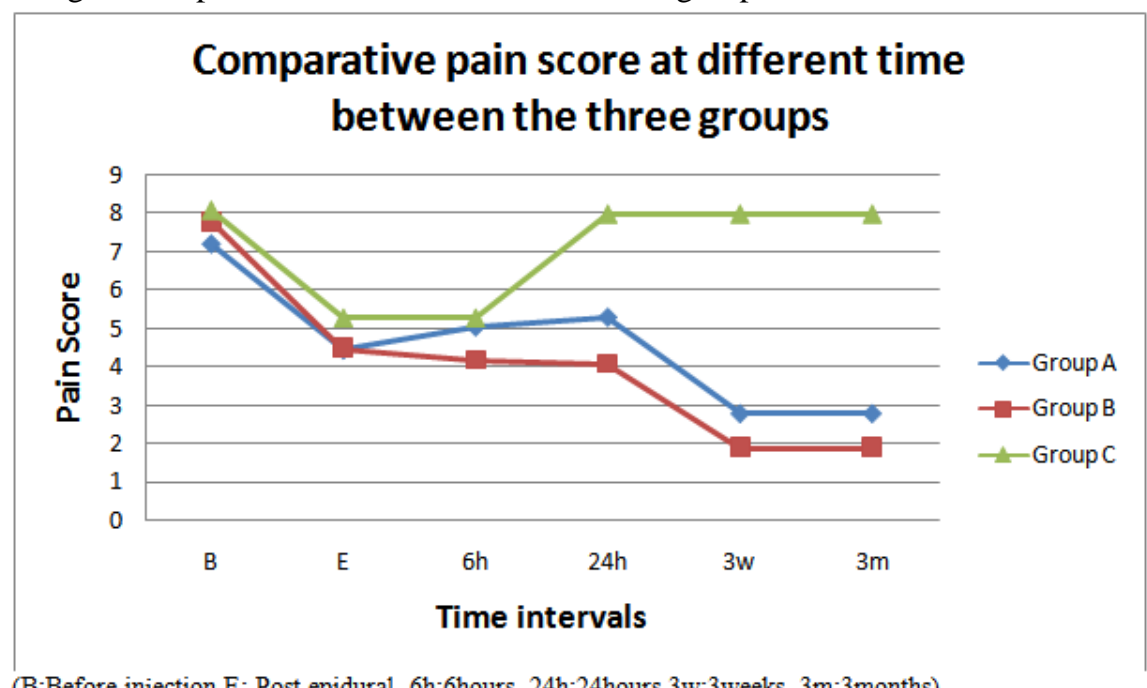

Table - 2 Comparative SLR improvement (Mean) in the three groups.

- $\quad$ Post epidural injection

- 3 weeks

- 3 months

\begin{tabular}{|l|l|l|l|}
\hline Time interval & Post epidural inj. & 3 weeks & 3 months \\
\hline Group 1 & 24.21 & 24.21 & 24.21 \\
\hline Group 2 & 27.5 & 27.5 & 27.5 \\
\hline Group 3 & 27.5 & 0 & 0
\end{tabular}

It can be seen from the above table that there was improvement in SLR in all the 3 groups just after the injection due to the effect of local anaesthetic, while in the $3^{\text {rd }}$ group there was no improvement in SLR at 3 weeks and 3 months period due to the absence of steroid in this group (Methyl Prednisolone). 